\title{
National Culture and the Model of Business Organization for the Case of Kosovo
}

\author{
Prof. Ass. Dr. Hysni TERZIU \\ University of Prizren "UKSHIN HOTI", Prizren, Kosovo
}

\begin{abstract}
The study of culture of businesses is important for the requirements that today the globalization sets. While the expending of business across borders is becoming more and more common, the national challenges are becoming more and more present. The underestimation of all these trends and their relationship to the culture may a reason for the increase of the number of existing or even of new businesses. The research aims at explaining at how have changed the dimensions of national culture during the initial years of transition and during the continues years. Which are the new values that dominate the business activities in Kosovo? Can we admit that the new values determine the models for activity coordination? The article provides an overview of the dimensions of culture as a determinant of the type of organization. It aims to show the approximate positioning in these structuring forms. The modeling shows at modest way the competitive advantages that the culture offers. The economic contribution of culture shows how should be the models for cordinating the activities which will be the trend in the future. The Twenty-first century is putting Kosovo businesses in front of new perspectives and new challenges, which are added to existing ones and which are becoming even more acute. These all seek even more the attention of their managers. The purpose of this paper is to provide an insight on how to be organized from the structural and human aspect in order to react according to the culture in many organizations with new innovative ideas, in accordance to the requirements of the time in order to have an effect on the social system, on lifestyle, on economic system and on the organization of units in this system. All these help on the definition of basic models of organizations with a strategic planning as a condition for intercultural integration and coordination - national and international.
\end{abstract}

Keywords: Businesses, culture, models, strategies, organization, activities, competition, innovations, national, international.

\section{Introduction}

The problem of many enterprises today lies at its structural and humane aspects. Therefore people react according to their culture and the ideas about how to be an enterprise should be part of this culture. From the dimensions of the culture should also appear the basic determinants of enterprises' models. They dictate the type of organizational model to be used by businesses in Kosovo, in order not to be much deviatiated from these dimensions. This could bring problems in adapting the practices of enterprise's culture with the total value of the Kosovar culture, so this will result with a total mismatch between the national culture and enterprise culture.

If Kosovo this would be treated in the framework of these two dimensions, position within a matrix would provide us with the possibilities to solve the problems of restructuring and other problems that have arisen today. Referring to the level of cultural dimensions analyzed in this paper, it can be concluded that Kosovo businesses are experiencing a shift from a high distance of power and low avoidance of uncertainty towards a society that today is characterized with two values: high distance of power and high avoidance of uncertainty.

According to the dimensions of culture we can observe a shift from the top-right quadrant to the bottom-right quadrant. So, the businesses in Kosovo are shifting from the model of organization based totally on family, where the managersubordinate relationship approximates the parent-child relationship and where the basis of organization was collectivism, 
towards the model which is called the pyramid of people. The director is on the head and other persons in are placed in different levels according to hierarchy. For Kosovo we have the transition from the "family" models (which were characterized with the concentrate of authority and the solution of conflicts was done permanently) to the "pyramid" models that provide the concentration of authority and the need of businesses to formalizing their activities.

So we talk today about models that have a relatively high distance of power, strong tendency to avoid uncertainty, individual work versus group work (related to individualism) and an ambition work more hostile than friendly (related to the degree of masculinity). The values about desired centralization and normalization affect structural models of organization.

\section{The dimensions of national culture and their impact on business culture}

Kosovo territory has dominated the history of civilization, production and the intensity of factors of production. There have been investment sectors in the labour factors (agriculture) and acute problems on the capital factor, technology, or on the human resources structures, their preparation through training according to the requirements of the time. These factors still have today effect on the social system, lifestyle, economic system and organization of the system units.

The development trends in Kosovo are strongly influenced by the culture of business development, as it is passing from the culture with great importance to the support group, to the undeniable individual rights. By minimizing the differences, harmony and loyalty in the group to the maximization of differences, confrontations and compromises oriented towards us and individualism¹.

The creation of new economic system, provided new values of cultural dimensions and different performances in the workplace

\section{Kosovar reality in the dimension of Collectivism- Individualism}

The group has been the primary social organizing in Kosovo. Today, this attribute is waning and is even risking disappearing the feeling of collectivism. The group-individual relationship includes a high degree the emotional appeal and at lower degree collectivist actions. Leaving the collectivism is reflected with: the emergence of private entrepreneurship, selfmanagement, individual performance problems and free competition. Here, the decision-making is centralized and the responsibility is defined. There are no production heroes or groups that dominate the work. There are no people that are sacrificed for the enterprounership but there people are with hided purposes. The voice of honesty does not exist.

The competition is becoming extreme. It is appeared more strongly among individuals rather than among groups. What motivate the individuals in Kosovo are the economic factor and not the social one. The individual position and his expected role will be relatively determined by how he understands his work and by how he carried his individual work. The solidarity in the group is partly emotional. It is not difficult to cross the members of the group and to work individually.

A person is involved in the group only if he has financial and emotional benefits. In many businesses in Kosovo, is tolerated the absence of harmony and loyalty. The individualistic nature in decision shows the individualistic trend in business. There is no a general consensus. This means that many rational ideas arise from individuals and put harmony into a question.

Capitalization in Kosovo did not start with state reforms, but with individual initiatives and with crises. This obviously reflects this individualistic trend. Today, the system of values avoids the feel of shame for yourself, for the firm or for the group work and the enables the emergence of superior skills in different individuals.

The majority of the workers believe that the business growth is for the reason of gain and only few of them believe that it is for social purposes. Not everything is evaluated in terms of whether it is good or bad for the company and the community.

1 Golden K., The individual and organizational culture: strategies for action in highly-ordered contexts, Journal of Management Studies, 29 
The fear of isolation suffered by Kosovars for decades sends towards the avoidance of conservatism and towards the encouragement of individual initiative.

Obligations are moral forces that make the individuals to engage in social activities. While there has been a more binding culture, today the trend is weakening it somewhat. So there are many situations in which the obligations are minimized and flexibility for their performance is maximised. Employees feel motivated by those who make them favours. For many times, we were taught not to be engaged with others, especially with foreigners, because we would be felt obligated and this would then complicate our lives. A Kosovar would be felt discomforted in a relationship that does not include the recognition or group relationship. Today, an individual is involved with fewer emotions in this relationship. New business contacts, dealing with immigration and the need for integration and development of this attribute, has changed.

Business structures today are defined less in terms of the group and more in terms of individual positions. Responsibilities are often defined in terms of tasks to be fulfilled only from special members of the organization. The request for individual freedom transcends the social emphasis. The education system in Kosovo today aims to provide customization of employee and administration with the management structures modelled on the basis of individual values and away from collective ones.

New cultural values strengthen the transition to individualism, enhance the status and increase the number of members with individualistic trend, so we are moving from collectivism to individualism, from emotional and moral involvement in more formal relationships. In Kosovo, the individual protects more his interests rather those of the organization. But there are situations where individuality does not get the importance and necessary care because: continue to exist favours, the work is not a sufficient reason to justify the maximum commitments and efforts, the fear of confrontation often send towards the lack of initiative and there may exist situations for the hiding of conflict ${ }^{1}$.

\section{1. The dimension of Power Distance on the Workplace}

From the previous system we have inherited a high affinity of authority and obedience. This trend has its influence today on the rate of power distance. The distance of power is not only reflected on the values of leadership, but also on the values of the followers. Businesses in Kosovo continue to be characterized by high power distance. We often find powerful workers, scared from changes which require autocratic leadership. This is shown in the centralization of structures, privileges for administrator, absence of consultation in decision-making and situations of inequality.

The power of leader is often absolute. This power, in most of the cases, is institutional and political rather than personal and is associated with profound changes of rank among individuals. The status that is possessed by a leader in Kosovo, not always is influenced by education, background, the length of service in the organization and from the measure of organization. In our units, exist in "principle" that the higher the salary is, the greater are the benefits of the individual and his prestige in the business unit or abroad².

The working environment coincides with the life of a small and traditional community, however, human relations are such that the organization does not give to the individual a full identity, because it does not offer a complete security and full income. This deepens even more distance of the power between leaders and subordinates.

However, today is noticed another trend that started in the public sector and which is more the trend of managers. The tendency is for a decrease in power distance, because managers are more satisfied with superior participants, they talk for informal consultations and for the delegation of authority. Workers require more initiative. There are authors who are less afraid to seek cooperation. But we should note that these trends are in their beginning development and are required more by the experts ${ }^{3}$.

\footnotetext{
${ }^{1}$ Frost P.J., Moore L.F., Louis M.R., Lundberg, C.C., \& Martin J., Organizational culture. Beverly Hills, CA: Sage, 1985

2 Geertz C., The Interpretation of Cultures, Basic Books, Inc., New York, 1973

${ }^{3}$ Greenwood R., Hinings C.R., Organizational Design Types, Tracks and the Dynamices of Strategic Change, Organization Studies, 9 , pg. 293-316
} 


\section{2. Dimension of uncertainty avoidance in organizations}

Across all societies is considered that whatever is variable, is also dangerous. This applies also to the enterprises in Kosovo and is closely related to the dimension for the avoidance of uncertainty. All are faced with the dilemma what will happen tomorrow. The future is uncertain. The avoidance of uncertainty is treated as the degree at which members feel threatened by unfamiliar situations. It reflects the willingness of the individual and society to accept it but also to control it.

How has this dimension been, and how it has changed over the years of transition and is expected to change in the future?

We can give some arguments that prove that Kosovo society is going from low avoidance of uncertainty to high avoidance of uncertainty.

The Kosovars have been living in a fully planned and centralized society. In such circumstances, the uncertainty does not exist and neither do exist the efforts of the society to avoid it. The neglecting of risk has started to be strongly suppressed with force or to be imposed by the possibility of space to allow centralized economy. But the fact is that they were raised soon after the year of 1999. The first thing that Kosovars start to do was the individual entrepreneurship, especially in trade. However, wanting to position the Kosovar society into a society that accepts the uncertainty or tends to avoid it, we talk about a slow shift from low avoidance to high avoidance (from acceptance to the control of uncertainty).

After 1999 and during the first years of transition, for Kosovars is noticed a growing trend towards risk-taking and a lower level towards the avoidance of uncertainty. This is justified by several facts: the desire for new things and for things that were unknown and forbidden for Kosovars, the lack of economic and political stability during the early years of transition, a favourable geographic location, a mentality of trader inherited particularly to some cities of Kosovo, an overdose of selfconfidence and dangerousness, responsible or irresponsible ignorance of uncertainty caused by the lack of information.

Today are concluded higher demands for the control of uncertainty. Kosovo managers are relatively conservatives and take a moderate level of risk, because often the relationships is open and effect negatively the level of confidence. And often they are contradictory or assume a high risk. As long as the uncertainty is considered as risk, then it is expressed as source of concern for the entrepreneurs as well as for the workers. In our organizations in not avoided at a desired level the conflict. Its avoidance and the achievement of harmony and justice are not supreme issues. Although there are no major advantages in staff and in their skills, managers are taught to become ambiguous, indirect, not credible, independent, uncertain to realize their business activities. Today, the demands by business leaders and by representatives of other foreign investors, either in written or unwritten rules, are growing

Competition is not avoided. The creation of individual and organizational consensus is not very preferred. The individual competition is observed nowadays more as natural thing that increases the uncertainty. In such conditions the effort for fair competition are in the forms of control of uncertainty.

In Kosovo we find cases where different individuals in the enterprise have varying degrees of acceptance of uncertainty, and for this they often have communication problems within the enterprise. This justifies the urgent need to plan the uncertainty, which means today, the need for more rules, written procedures, managers oriented totally toward their work, structured processes, reduced rates of turnover at work relying on practices known around the world ${ }^{1}$.

\section{Kosovar Reality in the Male dimension (Masculinity) and Female dimension (Femininity)}

The dimension is important for the success of an enterprise, but the optimal balance for various companies is different. "All societies' reserve the primary role for men while for women is reserved the support and care. Societies differ on the degree to which these roles are divided within the society ${ }^{2}$.

\footnotetext{
1 Friedman J., Culture and Global Systems, Theory, Culture \& Society 23 (2-3), 2004

2 Hofstede Geert, Hofstede Gert Jan, Cultures of Organizations: Software of mind, 2004, ISBN-13: 978-0071439596
} 
In every society, the relationship of roles is just as important as performance. Masculinity societies are based on values such as: challenges, recognition, achievement, advancement, profit. Feminist societies rely on strict role for the division between men and women.

Kosovo is not considered as a country with strong separation of gender, however, continues to exist a general sympathy for what is big, fast, and strong. In a traditional society, like the Albanian society, men are combative and the same is done today economically, in modern society. This is indicated in that women often have lower status than men, but this does not always suggest a performance oriented by men. Many women, for economic or career reasons are obliged to work for foreign firms or to move elsewhere. In our society, do not exist barriers regarding the questions on gender during the employment interviews, but regardless we cannot say that is provided an equal employment opportunities to woman as to men. In Kosovar businesses, we find these expectations interoperated at different levels for different individuals ${ }^{1}$.

Masculine values are presented through some indicators:

The current management methods of direction and decision-making authority.

The way on how are conflicts solved today within a unit or between them. Conflicts solutions are often for the interest of individuals rather than in the favour of the group or for the public interest.

The rate at which work is supportive for the individual's personal life. Life in Kosovo is being planned in the function of work, and this requires the emergence of new values such as ambition, competition, challenge, recognition. The polarization of women that seek career development opportunities and recognition of the tendency oriented more towards the work rather than toward the individual (within the unit), is increasing.

While in foreign literature is not discussed much the link between this dimension and the employment rate among men and women, in Kosovo this connection is apparent. Outside the house, the man continues to dominate, while many women accept a job with low status and low pay, not because they lack the desire for self-perfection but because there exists the need for survival. For every society, we can show that the development fits with the interest of young women and men. Their interests are more technical, while the elderly the interest are more socially interested. The former are considered as owner of masculine values while the others are owners of feminist values. Older persons are considered as human directors while the younger's as technical managers. Masculinity trend of culture organizations in Kosovo, is shown by the following analysis ${ }^{2}$.

\section{Aggressiveness, competition, achievement, motivation, sustainability}

The ways of education, guidance, support or independence are founded to be connected with the way on how the mother treats her child. This sets a level of aggressiveness, competitiveness spirit, the degree of achievement, motivation or sustainability.

In Kosovo, the mother does not push you toward full independence, therefore the level of aggressiveness is relative. The motivation arises from responsibility and reward. The achievement is oriented towards the merits that are required from the individuals to achieve his individual goals rather than those of the group. Work, in the previous system, is seen primarily as a tool to build a character and secondly was treated as productive activity. Today it is moving toward some new values related to work (challenge, competition, self-esteem, recognition). The personal success and achievements stand before the success of the enterprise, although they are everyday related more and more to show the importance that lye on social responsibilities and obligations. New industries are recognizing the new needs to learn continuously by developing skills and at the same time to be courageous about new knowledge, discoveries, or markets.

\footnotetext{
${ }^{1}$ Ministry of Trade and Industry, Agency for Support of SME-s, Report 2010-2014

2 Kosovo Agency of Statistics, Report 2013
} 
In order to ensure survival, Kosovo businesses must be incorporated quickly and strongly so as to penetrate into new markets or in the international businesses. This attitude is reinforce also by the facts or the nature of life that do not stay in a static state, but differ as a result of new trends or products with high technology.

Perseverance has been a relatively an integral part of education in Kosovo that means standing and not giving up, perseverance for work. Perseverance is a slogan of sustainability. The values of last culture are transmitted today in the form of patience, sustainability. By continuously emphasizing the new goals, enterprises must enhance the value of perseverance as a value that sends us towards improvement ${ }^{1}$.

So we have a society with masculine attributes despite the presence of significant efforts to change the situation over the last years. Masculinity in the workplace is justified by new values represented by men and women. Increase in the percentage of women that aim higher career (political, academic) developments of the feminist movement. A population with increased efforts for better-educated and for increased welfare. The people employed in masculine societies, are faced with challenges or problems that may not be present also in other countries. This is believed that will open problems also in the case of enterprises with foreign partners regarding the degree of dedication to work².

\section{How should be the model of organization of business units in Kosovo, depending on the dimensions of the organization culture?}

Today, the problem of many organizations lies on structural and human aspects. People react according to the culture and part of it is also the ideas on how an organization should be. Out of four dimensions of culture, only two are the main determinants of organizational models. Every organization model and organization structure requires us to answer two types of questions:

a. Who has the power to decide?

b. What rules or procedures should be followed in order to achieve the desired goals? (How to regulate and to structure the activities)

The answers to the above questions are founded in two dimensions of culture:

\section{1- Distance of power and}

\section{2- Avoidance of uncertainty}

They dictate the type of organizational model to be used by businesses in Kosovo, in order not to be noticed major deviations from these dimensions. This could bring problems in adapting the practices of the organization's culture with the total value of culture in Kosovo, which would result in a total mismatch of national culture and of organizational culture ${ }^{3}$.

To achieve this, we will use an already made matrix of organizational models. All of the matrixes positions could be explained according to a model organized into four types of structuring.

1- Pyramid model. Here the control principal is a hierarchical authority, a system of rules and personal authority above superior rules.

\footnotetext{
${ }^{1}$ Greenwood R., Hinings C.R., Organizational Design Types, Tracks and the Dynamices of Strategic Change, Organization Studies, 9 , pg. 293-316

${ }_{2}^{2}$ Golden K., The individual and organizational culture: strategies for action in highly-ordered contexts, Journal of Management Studies, 29

${ }^{3}$ Gerdhe S., National culture and model of business organization, Economy and transition. - Nr. 1, 2009, pg. 84 - 96
} 
2- Car model. According to this model, the concept of real authority derives from the rules, so the rules are those that govern us.

3- Model of the market organization, under which authority is not personal nor even rules, but it is completely to the market.

4- Family model. In these models authority is divided and has a high degree of collectivism.

If we would treat Kosovo in the framework of these two dimensions, positioning it within a matrix, it would give us ways to solve the problems of restructuring and other problems that have arisen today'.

Referring to the level of cultural dimensions analyzed above, we concluded that Kosovo businesses are experiencing a shift from high distance of power and low avoidance of uncertainty, towards a society that has today highlighted two values: high distance of power and high uncertainty avoidance.

Figure 1: Distance of power against uncertainty avoidance according to models²

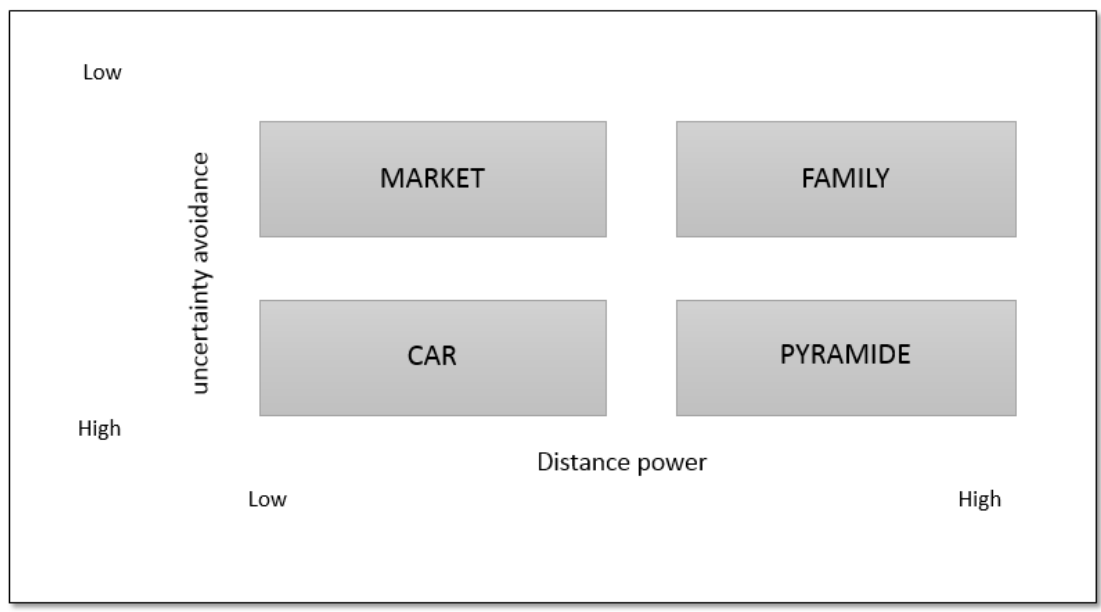

According to the dimensions of the matrix, can be observed a shift from top-right quadrant to the bottom-right quadrant. So, businesses in Kosovo are thoroughly crossing from family organization models, where manager-subordinate relationship approximates the parent-child relationship and where the basis of organization is collectivism, to the model that is called pyramid of people. The main person is in charge and the other persons are placed in other levels of the hierarchy.

We conclude that according to the relation between power distance and uncertainty avoidance, the organizations should be structured in such a way as to allow the adaptation of the cultural need and to the structural needs of the businesses. 
For Kosovo we have the transition from the "family" models (which were characterized with concentrated authority and the solution of conflicts was done permanently) to the "pyramid" models that provide the concentration of authority and the need of businesses to formalize their activities ${ }^{1}$.

So we talk today about models that have a relatively high distance of power, strong tendency to avoid uncertainty, individual work versus group work (related to individualism) and an ambition work more hostile than friendly (related to the degree of masculinity). The values about desired centralization and normalization affect structural models of organization.

The model selected from the matrix dictates the characteristics of organizations. About centralization desired values and normalization affect the structural models of organization.

Since we accepted the passage from the family model to the pyramid model, we can talk roughly what would be the preferred mechanism for the coordination of activities. From the surveys conducted is experienced a shift from simple structuring of businesses towards bureaucracy, and from the direct supervision towards the standardization of processes. For large enterprises, that have over 10 years of work, we can talk about normalization of behaviour, as part of the standardization of business processes. This will serve to control the activities, to coordinate the activities, to ensure sustainability, efficiency and justice for the clients².

Figure 2: Distance power against avoidance of uncertainty according to structure ${ }^{3}$

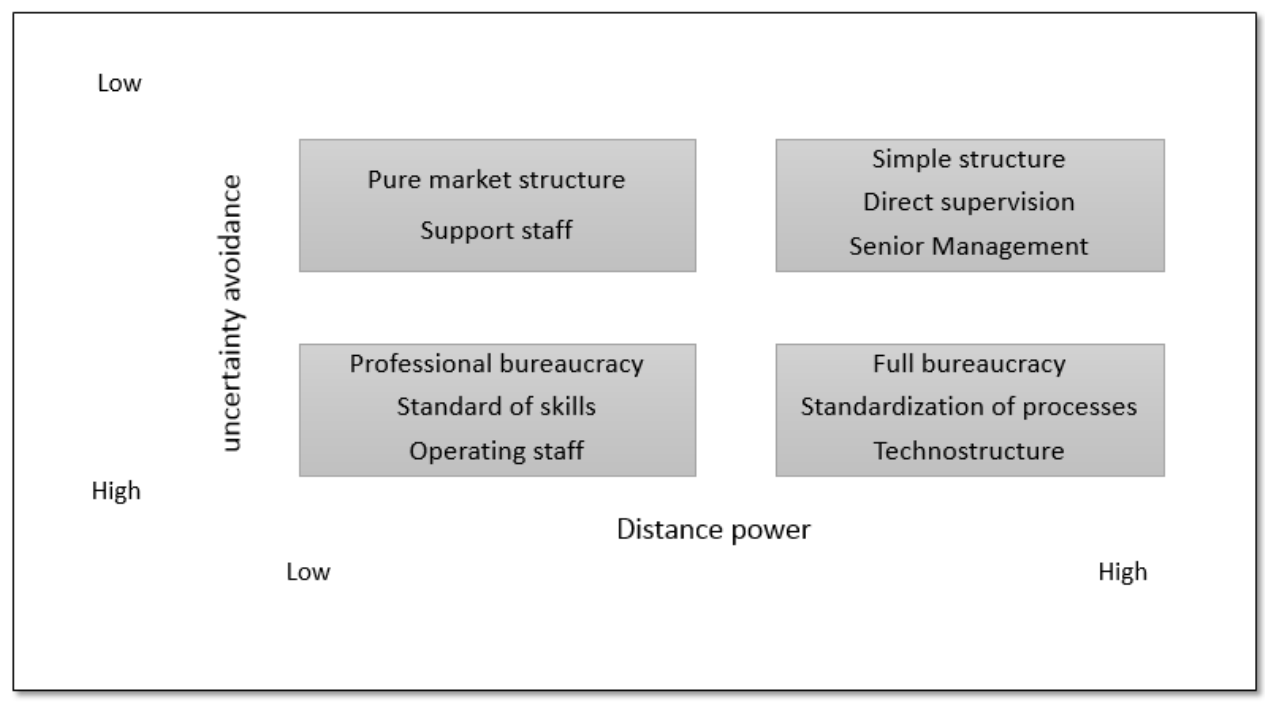

Passing along this matrix, will also affect the ways of planning and control, the ways of incentives, the leadership policies, decision-making policies and those of power. Passing along the matrix positions in Kosovo is thought as a slow process, in terms of malfunctioning of human institutions or the lack of a strict legislation. The transition to other positions is a perspective issue; we think that it will require awareness of society, increase of civil awareness and perfection of business ethics ${ }^{4}$.

\footnotetext{
${ }^{1}$ Ministry of Trade and Industry, Agency for Support of SME-s, Report 2010-2014

2 Geertz C., The Interpretation of Cultures, Basic Books, Inc., New York, 1973

${ }^{3}$ Gerdhe S., National culture and model of business organization, Economy and transition. - Nr. 1, 2009, pg. 84 - 96

${ }^{4}$ Friedman J., Culture and Global Systems, Theory, Culture \& Society 23 (2-3), 2004
} 


\section{Conclusions}

Kosovo Culture presents this cultural profile:

The shift from collectivist to individualistic trends. The individual protects his/her interests rather those of the organization. Deviation from the important interpersonal relationships.

The try to avoid uncertainty is justified by high needs for planning, further written rules and procedures, job-oriented managers, structuring processes, reduced rates of job turnover. Managers who intend to risk but by relying on known worldwide practices.

A country with high power distance especially for organizations in the private sector. The tendency is to reduce the distance of power, because managers are more satisfied with the superior directors, they talk about informal consultations and for the delegation of authority. Workers require more initiative.

Planning, the control of uncertainty and individualistic trend increase the quality requirements for market orientation.

Societies with highlighted masculine traits. Masculinity in the workplace justified with new values embraced by men and women. Increase in the percentage of women who are career oriented. There are developments in the feminist movement. A population with increased efforts for better education and better welfare.

Cultural dimensions affect the models of business organization. The transition from family models to the pyramid models will help strategic planning as a condition for intercultural integration and coordination.

\section{Summary}

The premise for the development in Kosovo is strongly influenced from the development of business culture, since culture is going from the support of the group to the undeniable individual rights.

Business structures today are defined less in terms of the group and more in terms of individual positions. Often, responsibility is defined in terms of tasks that need to be fulfilled only from the special members of the organization. The demand for individual freedom transcends the social emphasis. The education system in Kosovo today aims to provide better match between the employee and administration with the management structures modelled on the basis of individual values and very far away from collective values.

New cultural values make easier the transition to individualism, enhance the status and increase the number of members with individualistic trend, so we are moving from collectivism to individualism, from emotional and moral involvement to more formal links. In the case of Kosovo, the individual protects more his own interests rather than those of the organization. But there are also situations where the individuality does not get the necessary importance and care because: continue to exist "favours", the work is not a sufficient reason to justify the maximum commitment and effort, the fear of confrontation often leads towards the lack of initiative and situations for the concealment of conflict.

However, today is noticed another trend that started in the public sector and that is the trend that is leaded more from the managers. The trend is for a decline in the distance power because managers are more satisfied with superior participants; speak more for informal consultations and fro the delegation of authority. Workers require more initiative. There are authors that are less afraid to seek cooperation. But we note that these trends are in their infancy level and are required more from the experts.

Across all societies is considered that whatever is variable, is also dangerous. This applies also to the enterprises in Kosovo and is closely related to the dimension for the avoidance of uncertainty. All are faced with the dilemma what will happen tomorrow. The future is uncertain. The avoidance of uncertainty is treated as the degree at which members feel threatened by unfamiliar situations. 
In Kosovo we find cases where different individuals in the enterprise have varying degrees of acceptance of uncertainty, and for this they often have communication problems within the enterprise. This justifies the urgent need to plan the uncertainty, which means today, the need for more rules, written procedures, and managers oriented totally toward their work, structured processes, reduced rates of turnover at work relying on practices known around the world.

\section{References}

[1] Greenwood R., Hinings C. R., Organizational Design Types, Tracks and the Dynamices of Strategic Change, Organization Studies, 9, pg. 293-316

[2] Golden K., The individual and organizational culture: strategies for action in highly-ordered contexts, Journal of Management Studies, 29

[3] Geertz C., The Interpretation of Cultures, Basic Books, Inc., New York, 1973

[4] Hofstede Geert, Hofstede Gert Jan, Cultures of Organizations: Software of mind, 2004, ISBN-13: 978-0071439596

[5] Frost P. J., Moore L. F., Louis M. R., Lundberg, C. C., \& Martin J., Organizational culture. Beverly Hills, CA: Sage, 1985

[6] Friedman J., Culture and Global Systems, Theory, Culture \& Society 23 (2-3), 2004

[7] Gerdhe S., National culture and model of business organization, Economy and transition. - Nr. 1, 2009, pg. 84 - 96

[8] Ministry of Trade and Industry, Agency for Support of SME-s, Report 2010-2014

[9] Kosovo Agency of Statistics, Report 2013 